\title{
¿Víctimas de primera o de segunda categoría? La compleja construcción social de una “jerarquía de las víctimas" en la Argentina posdictadura (1983-1987)
}

\author{
Victims of first or second category? The complex social \\ construction of a "hierarchy of victims" in Argentina post- \\ dictatorship (1983-1987)
}

\author{
Soledad Lastra \\ Instituto de Altos Estudios Sociales, Universidad Nacional de San Martín \\ Consejo Nacional de Investigaciones Científicas y Técnicas \\ lastra.soledad@gmail.com
}

\begin{abstract}
Resumen
Los desaparecidos y los campos de concentración de la última dictadura militar, fueron consagrados como las figuras principales excluyendo a otros sectores de afectados. Este artículo se propone analizar el proceso de construcción social de una "jerarquización de las víctimas" desplegado en los años ochenta en la transición a la democracia en Argentina. Para historizar este proceso, este trabajo analiza el papel de actores sociales y de organismos de derechos humanos, especialmente del equipo de Salud Mental del Centro de Estudios Legales y Sociales. Este equipo trabajó en la atención psicológica a los exiliados argentinos que regresaron al país desde 1983. La hipótesis que guía este artículo señala que en el proceso de "jerarquización de las víctimas", entre 1983 y 1987, existieron prácticas de mistificación, estigmatización y autosilenciamiento por parte de ciertos actores del campo de los afectados que se combinaron con límites conceptuales y analíticos a los que se enfrentaron los trabajadores de la salud mental para comprender los efectos de la violencia estatal.
\end{abstract}

\section{Palabras Clave}

Víctimas; desaparecidos; Madres de Plaza de Mayo; terrorismo de Estado; salud mental

\begin{abstract}
Disappeared persons and concentration camps were consecrated as the main figures of the victims of the last military dictatorship, excluding with this other types of grievances. This article aims to analyze the social construction of a "hierarchy of victims" deployed in the eighties during the transition to democracy in Argentina. To historicize this process, the paper analyzes the role of social actors and human rights organizations, focusing especially the mental health team of the Center for Legal and Social Studies. This team worked in the psychological attention to the Argentine exiles who returned to the country since 1983 . The hypothesis that guides this article indicates that in the process of "hierarchy of the victims", between 1983 and 1987, there were mitifcation, stigmatization and self-rehearsal practices by certain actors in the field of victims that were combined with conceptual and analytical limits faced by mental health workers to understand the effects of state violence.
\end{abstract}

Esta obra está sujeta a la Licencia Reconocimiento-NoComercial-CompartirIgual 4.0 Internacional de Creative Commons. http://creativecommons.org/licenses/by-nc-sa/4.0/

(cc) BY-NC-SA 


\section{¿Víctimas de primera o de segunda categoría? La compleja construcción social de una "jerarquía de las víctimas" en la Argentina posdictadura (1983-1987)}

\section{Keywords}

Victims; disappeared; State terrorism; transition to democracy; mental health

\section{Introducción}

La dictadura militar argentina que se instaló el 24 de marzo de 1976 implementó un modelo represivo singular y conectado con los regímenes autoritarios del Cono Sur cuyo mecanismo central fue el secuestro y la desaparición forzada de personas (Slatman y Serra Padrós, 2014). La transversalidad social y la masividad del daño ocasionado por la desaparición fueron características del terrorismo de Estado desplegado en este país (CADHU, [1977] 2017; Duhalde, [1983] 2014). Sin embargo, como señala Virginia Vecchioli (2001) ello no implica necesariamente el automático reconocimiento de los desaparecidos como víctimas por excelencia de la última dictadura.

Como muestra Marina Franco (2018), durante los años ochenta, en el marco de las negociaciones de los partidos políticos con los militares en el poder, los desaparecidos se convirtieron en un problema de gobernabilidad dejando por fuera de la agenda otros temas de la represión. Es decir, que no hubo una repercusión política inmediata que atendiera el reclamo de los familiares de desaparecidos sino que hizo falta que esta figura se convirtiera en un problema interno de la propia dinámica política transicional para alcanzar un alto grado de protagonismo.

La sobre representación de la desaparición como efecto represivo de la última dictadura también se refleja en el campo académico. Sólo en los últimos años se fue ampliando la agenda de temas sobre otras formas represivas -como la cárcel y el exilio, y sus efectos- comenzando a interpelarlas en conflicto o conexión con la desaparición como paradigma de la violencia estatal (Águila 2013; Águila, Garaño y Scatizza, 2016; D’Antonio, 2018; Jensen y Montero, 2018; Jensen y Lastra, 2014; Merenson, 2014).

En este marco, en el presente artículo nos proponemos analizar y desnaturalizar el proceso de jerarquización del dolor producido por la última dictadura militar argentina. ${ }^{1}$ Nos referimos a una "escala" del daño ocasionado por la represión

\footnotetext{
${ }^{1}$ Este trabajo forma parte del proyecto de investigación "Historia de las redes de asistencia psicosocial a los retornados del exilio en Argentina (1982-1990)" que dirijo en el marco de la Agencia Nacional de Promoción Científica y Tecnológica (Argentina) y con su financiamiento para el período 2018-2020. Fue presentado y debatido en distintos ámbitos académicos a los que quiero subrayar mi agradecimiento. Al Seminario de Historia Social organizado por El Colegio de México y dirigido por la Dra. Clara Lida, la Dra. María Dolores Lorenzo, el Dr. Diego Pulido Esteva y el Dr. Mario Barboza Cruz, que me brindaron un espacio fundamental para desnaturalizar nociones nativas que guiaban los interrogantes iniciales. Por otro lado, este texto fue sometido a las agudas lecturas de mis colegas del Núcleo de Historia Reciente del IDAES-UNSAM y del Dr. Luciano Alonso, quien contribuyó con sus comentarios en el tercer encuentro de la Red de Estudios sobre Violencia Política y
} 


\section{Soledad Lastra}

estatal así como a una clasificación sobre las consideraciones sociales acerca de esos daños o sufrimientos (Canelo y Guglielmucci, 2005; Franco, 2006; Jensen, 2008; Vecchioli, 2014). Sin llegar a cristalizarse en una teoría formal o explícita pues se vincula con representaciones sociales presentes en prácticas y discursos, la "jerarquización" generalmente pondera la imagen de los desaparecidos y de los niños apropiados como las "víctimas" por antonomasia de la última militar a las que luego seguirían los ex presos políticos y los exiliados, entre otros afectados. Hasta ahora, este problema ha sido analizado para el caso de los sobrevivientes de los centros clandestinos de detención cuyas voces fueron a la vez legitimadas y desautorizadas por actores sociales del campo de los derechos humanos (Feld y Messina, 2014); y también para el caso de los ex combatientes y sobrevivientes de la Guerra de Malvinas cuyas memorias se construyen desde la comparación con otras experiencias internas a la guerra (mayor legitimidad por haber combatido en el campo de batalla) y sociales (mayor validez por la cercanía con la muerte o por haber sufrido más bajo la dictadura) (Rodríguez, 2014).

Como ha señalado Santiago Cueto Rúa (2010:134-135) la operación de clasificación sobre las víctimas se encuentra en las dinámicas internas del mismo campo de afectados, reflejándose en disputas morales y políticas sobre la legitimidad de la palabra de los represaliados y sobre sus membresías a determinados grupos. Junto a ello, retomamos las reflexiones de Andrea Rodríguez (2014: 348-349) para destacar que si bien se trata de jerarquías que pueden ser comprensibles desde la mirada de los sujetos, no dejan de producir dolor sobre las personas y efectos esencializadores (y silenciadores) en sus memorias.

Nuestro interés consiste en analizar mucho más el proceso que sus efectos. En este sentido, nos proponemos examinar históricamente la construcción de este imaginario "jerarquizador" durante los primeros años de la transición a la democracia sin descuidar algunos elementos que estuvieron presentes desde los últimos años de la dictadura militar. Para ello, ingresamos al problema desde el campo de estudios de los exilios, es decir, desde una de las "bases" o márgenes de este proceso piramidal. Recurrimos al trabajo realizado por el equipo de Salud Mental de la Oficina de Solidaridad con el Exilio Argentino (OSEA) del Centro de Estudios Legales y Sociales (CELS). Abocado a la atención psicológica de los exiliados argentinos que regresaron al país desde 1983, el equipo OSEA-CELS fue produciendo un marco teórico y clínico que incluyó a los exiliados como parte del universo de las víctimas aunque este proceso no llegó a consagrarlos como tales. Por distintos factores internos y externos que analizaremos aquí, el exilio como dispositivo represivo y los exiliados como sus efectos, quedaron rezagados del campo de las víctimas, mientras que paralelamente se acrecentaba el reconocimiento de otros sectores de afectados. Miramos especialmente el trabajo en

Represión en Rosario (abril de 2019). Quiero agradecer también a Santiago Cueto Rúa y a Cecilia Azconegui por sus preguntas atentas a la versión preliminar de este trabajo y a los evaluadores de la revista Páginas por sus sugerencias. Este análisis es deudor de todas esas voces. Todo lo dicho aquí es de mi entera responsabilidad. 


\section{¿Víctimas de primera o de segunda categoría? La compleja construcción social de una "jerarquía de las víctimas" en la Argentina posdictadura (1983-1987)}

salud mental pues advertimos que ciertos saberes y prácticas que se fueron desplegando en el campo "psi" a nivel micro pudieron amalgamarse con otros procesos sociales y políticos externos, reforzando la constitución de un "escalafón". Cabe aclarar que entendemos a la salud mental como un paradigma del campo "psi" a la vez que como una posición política adoptada por los propios actores. Desde principios de los años setenta en Argentina los trabajadores de la salud mental asumieron un enfoque antipsiquiátrico de la salud, concibiéndola como el resultado de una articulación de variables que incluyeron lo político, lo social y lo familiar. Este nuevo paradigma, profundizado por el encuentro entre el marxismo y el psicoanálisis y por la urgencia de comprender el desarrollo psíquico a partir de sus contextos sociales de producción, implicó múltiples tensiones al interior del campo "psi" así como nuevos roles para los profesionales de la salud (Carpintero y Vainer, 2018; Chama, 2015, p. 81). En Argentina, el campo de la salud mental fue duramente reprimido por la dictadura, lo que generó la desarticulación de proyectos inéditos de atención integral, el asesinato, cesantía y exilios de centenares de personas. ${ }^{2}$ Así, la iniciativa de la OSEA-CELS resultó novedosa porque retomó un proyecto de salud mental interrumpido por la dictadura militar y porque permitió considerar al exilio como una experiencia traumática con características propias.

En relación a las fuentes, hemos consultado el fondo documental del Equipo de Salud Mental del CELS y documentos producidos por la OSEA y por la Comisión Argentina para los Refugiados (CAREF). Esta última institución trabajó transitoriamente junto a OSEA en la recepción a los retornados argentinos ejecutando programas puntuales de reinserción social (1984-1985). ${ }^{3}$ De estas fuentes recuperamos documentos institucionales, ensayos inéditos, informes y proyectos de atención psicológica, expedientes y legajos producidos por asistentes sociales y psicólogos que trabajaron en las reuniones con retornados del exilio atendidos por el equipo de salud mental mencionado. También utilizamos entrevistas propias ${ }^{4} \mathrm{y}$ otras consultadas en el Archivo de la Palabra de la Universidad Nacional Autónoma de México (UNAM), para ilustrar algunas dimensiones de las representaciones y prácticas de los exiliados retornados que abonaron a este escalafón.

\footnotetext{
2 El campo de la salud mental fue uno de los más afectados por la represión estatal en Argentina, dejando un doloroso saldo de exiliados, torturados y al menos 397 trabajadores y estudiantes desaparecidos (Carpintero y Vainer, 2018, pp. 378 y 390).

${ }^{3} \mathrm{Si}$ bien OSEA estuvo conformada por actores del movimiento de derechos humanos que contribuyeron en las tareas de asistencia jurídica y social (como el COPEDE, MOVIP, SERPAJ, $\mathrm{MEDH}$ ); en lo que respecta a la atención psicológica, convocó a profesionales de la salud que habían ocupado cargos en la función pública previamente a la dictadura, otros que eran docentes en la Universidad de Buenos Aires y a trabajadores sociales que provenían de distintos organismos afines. Este último aspecto sobresale pues, como analizamos en otro trabajo, se requería que los profesionales demostraran su compromiso con la defensa de los derechos humanos (Lastra, 2019).

${ }^{4}$ Excepto en los casos en que se aclara el nombre, en todas ellas se decidió utilizar iniciales para preservar la identidad de los entrevistados.
} 


\section{Soledad Lastra}

Este texto se organiza en dos partes. En la primera parte reconstruimos las particularidades del proceso político y social más general de los años ochenta, analizando el posicionamiento de ciertos organismos de derechos humanos y de los mismos exiliados-retornados en este proceso "jerarquizador". En la segunda parte, examinamos específicamente el trabajo del equipo de salud mental OSEA-CELS, recuperando las clasificaciones que fueron construyendo sobre los casos y los efectos que tuvo para sus análisis el uso del concepto "terrorismo de Estado". En las conclusiones ofrecemos algunas líneas que pueden contribuir a una agenda más amplia sobre esta problemática.

\section{Marcos de producción de la "jerarquización de las víctimas"}

Como anunciamos, la categorización de "víctima" es producto de una construcción política y social que implicó disputas dentro del campo político y de los derechos humanos en Argentina. Nos detendremos en las dimensiones macro del proceso que lo fueron delineando.

En primer lugar, atendiendo a la dimensión político-estatal, las primeras medidas tomadas por el nuevo gobierno constitucional se concentraron en fortalecer la búsqueda de verdad y justicia: primero investigando el destino de las personas secuestradas y desaparecidas (creación de la Comisión Nacional para la Desaparición de Personas, Decreto 187/83 del 19/12/1983) y luego, juzgando todo acto de violencia criminal por parte de las organizaciones de izquierda armada (Decreto 157/83) como de las autoridades estatales del gobierno de facto anterior (Decreto 158/83). Al contrario de lo sucedido en otras experiencias transicionales del Cono Sur -como Chile y Brasil-, en Argentina la amnistía sancionada por los militares antes de dejar el poder fue declarada insanablemente nula (Ley 23.040 del $22 / 12 / 1983$ ) de manera que, en lo inmediato, fueron compelidos a declarar por sus crímenes. Por su parte, los dirigentes y militantes de las organizaciones revolucionarias fueron mantenidos en prisión cumpliendo condenas impartidas por la justicia militar. Esta posición judicial que equiparó la violencia estatal con la violencia política civil se convirtió en el pilar de la llamada "teoría de los dos demonios", discurso que alimentaron los organismos de derechos humanos durante la transición a la democracia en Argentina (Franco, 2014). Así, en los primeros años del gobierno de Alfonsín se concretó la condena social a la represión implementada por el Estado y también a la militancia en proyectos políticos revolucionarios en un sentido amplio (Franco, 2018). Ello impactó en el retorno de los exiliados que sólo entre 1983 y 1984, debieron tramitar más de dos mil habeas corpus preventivos para poder ingresar al país sin problemas judiciales (Lastra, y Jensen, 2014).

La judicialización sobre el exilio se profundizó en el marco del Juicio a las Juntas Militares entre abril y septiembre de 1985. El juicio, hecho inédito para el Cono Sur, condenó a militares de alto rango por la planificación y puesta en marcha de un proceso criminal masivo que incluyó a la desaparición de personas como metodología central. Junto a ello, fue creciendo la persecución judicial sobre los exiliados y retornados pues desde 1985 y especialmente entre 1986 y 1987, se 


\section{¿Víctimas de primera o de segunda categoría? La compleja construcción social de una "jerarquía de las víctimas" en la Argentina posdictadura (1983-1987)}

abrieron causas penales sobre ellos, lo que en algunos casos produjo nuevos exilios (o re exilios). Este clima judicializador incidió también en los sobrevivientes de los centros clandestinos de detención que debían participar como testigos ante los juicios y que en varios casos, se sintieron condicionados a no hacerlo o a testificar desde el extranjero (González Tizón, 2018). Este proceso contribuyó al silenciamiento político y social de la experiencia del exilio, generando sospechas por parte del poder político hacia estos actores (Jensen, 2008 y 2014; Yankelevich, 2009).

Las políticas estatales hacia los exiliados argentinos tuvieron un importante componente criminalizador. Sin embargo, ello no alcanza para explicar el lugar marginal que tuvieron en el campo de las víctimas. Otros actores cuyos discursos y prácticas incidieron en este proceso fueron los organismos de derechos humanos y los mismos exiliados. Nos detendremos en cada uno de estos actores rastreando aquellos elementos que, en dictadura y en los primeros años de la democracia, intervinieron en este proceso de jerarquización.

Durante la dictadura, los organismos de derechos humanos no hicieron del exilio un elemento de la demanda pública. A diferencia del caso chileno o uruguayo, en los reclamos de organismos de familiares de detenidos-desaparecidos o de presos, no se produjo una articulación de la demanda por el retorno del exilio (Lastra, 2016 y 2017). En el caso argentino, la agrupación Madres de Plaza de Mayo se fue constituyendo en vocera de los hijos desaparecidos fortaleciendo desde 1977 el reclamo social de "aparición con vida" y "castigo a los culpables" (Jelin, 2005). Sin embargo, este proceso no estuvo exento de tensiones. Laura Bonaparte, psicoanalista, exiliada en México en febrero de 1976 y madre de una hija desaparecida, señalaba:

"Con Madres nosotros tenemos una relación muy desgraciada, todo el exilio, no solamente yo. Teníamos prohibido usar el pañuelo [...] las Madres viajaban y yo me enteraba después que se habían ido. Y cuando me enteraba y les pedía cita, nunca nos daban cita. Yo era la madre subversiva en el exterior" (Entrevista a Laura Bonaparte, realizada por Pablo Yankelevich, Ciudad de Buenos Aires, 3 y 6 de agosto de 1999, pp. 59-61. PEL/2/A/6, Archivo de la Palabra, UNAM, México).

El relato de Bonaparte nos permite identificar un factor importante en la construcción de esta jerarquización de los efectos de la represión: la incidencia que la misma agrupación de Madres, constituida en voz hegemónica en el país, tuvo hacia afuera, "desautorizando" las voces de otros actores. En ese sentido, el carácter "subversivo" del exilio -que también aparecía vinculado a la campaña psicológica llevada adelante por los militares en el poder- impregnaba los discursos y prácticas de organismos que se iban ubicando como vanguardias de la lucha antidictatorial (Balbino, 2015; Franco, 2006). En la entrevista, Bonaparte remarcaba cierto uso que habrían hecho las Madres de las redes construidas en el exilio a la par que clausuraban la posibilidad de que fueran los mismos exiliados los que, en 


\section{Soledad Lastra}

determinados foros y encuentros internacionales, pusieran su voz para la denuncia: "ellas aceptaban nuestros contactos pero no aceptaban nunca jamás presentarse con nosotras" (Entrevista a Laura Bonaparte, op. cit., p. 67). Un matiz a esta afirmación lo introduce la psicoanalista y exiliada Beatriz Aguad, quien explica esta ausencia del exilio en la denuncia por el miedo que muchos expatriados sentían ante las represalias que la dictadura militar podía haber tomado con los familiares y amigos que permanecían en el país (Entrevista a Beatriz Aguad, realizada por Cecilia Guerrero, Ciudad de México, 21 de noviembre de 1997, 4 y 12 de marzo de 1998, PEL/1/A/29, Archivo de la Palabra, UNAM, p. 47).

El proceso de jerarquización nos remite entonces a un conflicto de voces iniciado en dictadura, entre las Madres y los exiliados. A ello debemos agregarle que, en el proceso de conformación de la denuncia realizada desde los países de exilio, también se fue diagramando una compartimentación de la información sobre la represión en la que se fue excluyendo al exilio de los repertorios de la represión. En México, por ejemplo, se formó la Comisión de Solidaridad con Familiares de Desaparecidos en Argentina (COSOFAM) que trabajó conjuntamente con el Movimiento de Trabajadores de la Salud Mental creado por exiliados argentinos y sudamericanos en ese país. ${ }^{5}$ Desde estos espacios se reunían los relatos de sobrevivientes y familiares de desaparecidos que se encontraban en el exilio, con el fin de presentarlos en los distintos foros para la denuncia. Los relatos, devenidos en testimonios, nacían del trabajo clínico de Mimí Langer, Ignacio Maldonado y Beatriz Aguad que se distribuían los casos clasificando las experiencias represivas: los dos primeros se ocupaban de los sobrevivientes de centros clandestinos de detención, mientras que Aguad se dedicaba a la situación de los ex presos políticos y de los familiares detenidos en el país. ${ }^{6}$ En consecuencia, se encuadraban los efectos de la represión en dos grandes áreas "centros clandestinos" y "cárcel”, dejando al exilio por fuera. Los informes que luego se presentaban en foros y organismos internacionales respondían a esta fragmentación represiva que, como veremos en el próximo apartado, aparecía con grandes conexiones en el trabajo de atención psicológica a los exiliados.

El proceso de jerarquización parece responder entonces a un distanciamiento que se fue generando durante la dictadura entre el exilio y otras experiencias represivas. Sin embargo, como ya ha señalado Luciano Alonso (2008), existieron importantes vínculos entre los organismos de derechos humanos en el país con los del exilio, aunque contradictoriamente, ello fortaleció la denuncia parcializada sobre los dispositivos represivos implementados por la dictadura.

Mirando los primeros años de la democracia es posible identificar otros discursos y prácticas en torno a las Madres y a la figura del desaparecido que contribuyeron a consolidar su lugar hegemónico en el "escalafón” del dolor. Por ejemplo, la psicóloga

\footnotetext{
${ }^{5}$ Este grupo brindó apoyo terapéutico a exiliados argentinos y latinoamericanos en general, recuperando la experiencia profesional y política que habían tenido en el campo del psicoanálisis argentino en los años sesenta y setenta (Manzanares, 2016).

${ }^{6}$ Entrevista a Beatriz Aguad, op.cit, pp. 46-48.
} 


\section{¿Víctimas de primera o de segunda categoría? La compleja construcción social de una "jerarquía de las víctimas" en la Argentina posdictadura (1983-1987)}

Raquel Bozzolo -por entonces integrante del equipo de salud mental de la agrupación Madres-, señalaba que existía sobre ellas una idea "mistificadora" del daño que soportaban por la desaparición de un familiar y de la acción que llevaban adelante en la búsqueda de verdad y justicia. Enfatizaba:

"los profesionales que hemos trabajado cerca de estas personas [Madres], muchas veces hemos hallado preservado lo que esperábamos encontrar dañado [...] encontramos incluso un nuevo desarrollo psíquico basado en nuevas identificaciones que fortalecieron y desarrollaron el Yo de las supuestamente "más dañadas" víctimas de la represión" (Bozzolo, 1986: 102.).

Aquí se subraya un aspecto central del proceso de jerarquización que se fue elaborando en los años ochenta: la unificación de las víctimas directas de la represión y de los "afectados" por parentesco, que homologó en el campo de las "víctimas inocentes" experiencias distintas de la violencia estatal. Así, "las víctimas más dañadas" a las que aludía Bozzolo, no eran sólo los desaparecidos sino también los familiares que debían vivir con esa figura. ${ }^{7}$ En este sentido, como han señalado Feld y Messina (2014: 57), las Madres y también la agrupación de Abuelas se convirtieron en voces autorizadas en el campo de la escucha social sobre la represión pues fueron a la vez víctimas y testigos. Bozzolo agregaba que en esta operación se investía a las Madres en "seres casi fuera de lo terrenal", lo que producía un efecto de profunda diferenciación en el campo social:

"estas santificaciones -o más bien esta actitud mistificadora- vuelve a introducir una fractura en el seno de nuestra sociedad [...] tiene consecuencias en el nivel político al restar fuerzas que podrían unirse al Movimiento de Derechos Humanos" (Bozzolo, 1986: p. 103).

No es la intención de este trabajo cuestionar o poner en duda la legitimidad del reclamo de las Madres por la aparición de sus hijos -aspecto con el que comulgamos política y éticamente- sino subrayar cómo en el desarrollo de su lucha pudo delinearse un carácter heroico o idealizado que impactó en el posicionamiento de otros sectores afectados por hechos represivos diferentes.

El protagonismo pujante de Madres se expresó en la legitimidad social que fue adquiriendo su lucha para el resto de los actores sociales. Si bien este reconocimiento no fue inmediato a la caída de los militares sino que se fortaleció con las decisiones tomadas por el gobierno de Alfonsín de juzgar los crímenes estatales (Franco, 2018), lo cierto es que en el campo de los derechos humanos y de la salud mental en particular, se constituyeron en portavoces privilegiadas. Para Luciano Alonso (2008: 8) ello se debió en parte, al nuevo modo de resistencia que proponía la agrupación: mucho más enraizado en lo emocional que en un proyecto político o revolucionario. Mientras las integrantes de Madres fueron depositarias de

\footnotetext{
${ }^{7}$ Agradezco a Cecilia Azconegui por resaltar esta diferencia.
} 


\title{
Soledad Lastra
}

sentidos icónicos sobre ellas y sus luchas, la figura de sus hijos, los desaparecidos, atravesaba un proceso similar. ${ }^{8}$

En ese proceso, los mismos exiliados que retornaban en los ochenta, se posicionaban reconociendo ese protagonismo. Una entrevistada, sobreviviente de un campo clandestino, señala:

\begin{abstract}
"desde el exilio uno lo que denunciaba era eso, la desaparición, dónde están nuestros seres queridos, entonces el exilio pasaba a segundo plano porque en definitiva aquéllos que habían podido salir del país [...] era producto del terrorismo de Estado, el desarraigo, el empezar de nuevo, las dificultades para insertarse en la sociedad [...] pero todo eso al lado de la desaparición..." (Entrevista a A.C., 11/10/2013, Buenos Aires.)
\end{abstract}

La imposibilidad de que los exiliados inscribiesen su experiencia como parte del mecanismo represivo estatal tuvo su correlato en la ausencia de una agrupación propia. A diferencia del caso chileno o uruguayo, que contó con agrupaciones de Familiares de Exiliados o de los mismos exiliados retornados en las transiciones, en Argentina existieron algunos intentos con poca proyección. ${ }^{9}$ Como subraya Silvina Jensen (2014: 185), existió un importante componente "no reflexivo" por parte de los exiliados que abonó a la construcción de un relato apolítico sobre el exilio, que no explicaba las verdaderas razones de la partida y que impidió que se reconocieran como víctimas legítimas del proyecto dictatorial. ${ }^{10}$

En este punto, debemos considerar que si bien los argentinos en el exilio lograron articular una importante red de denuncia y solidaridad antidictatorial, en el retorno este no fue un capital político importante (Roniger, Senkman, Sosnowski y Sznajder, 2018: 100). Muchos se asumieron como activistas humanitarios pero sin tener un reconocimiento social y político de las "batallas" dadas en el exterior. En ese sentido, la "jerarquización" del sufrimiento también estuvo determinada por la invisibilidad política que tuvieron los retornados del exilio y por su escasa incidencia en el

\footnotetext{
8 Marta L'Hoste (1986: 107), psicóloga e integrante del equipo de salud mental de la agrupación de Madres, señalaba que las intervenciones de las Madres en el espacio público estaban instituyendo a la figura del desaparecido con gran reconocimiento por parte de toda la comunidad.

${ }^{9}$ A lo largo de nuestras investigaciones hemos podido corroborar dos intentos claros de organización de los retornados del exilio: uno en septiembre de 1983 y otro en julio de 1984, ambos sin éxito (Movimiento Solidario de Salud Mental, Conclusiones al Encuentro de Salud Mental y Derechos Humanos, 25/09/1983, Buenos Aires; OSEA, Proyecto de prevención y asistencia en salud mental, $\mathrm{s} / \mathrm{f}$.).

10 Por ejemplo, B.F, exiliada en Alemania y retornada con su familia en junio de 1984 recuerda que en su primer trabajo estuvo más de seis meses sin poder contarle a sus compañeros que regresaba del exilio. "Sentía soledad, más que necesidad de hablar, uno siente necesidad cuando sabe que puede ser escuchada. De hecho yo sentía que no podía ser escuchada, había algo que no... que no cuajaba. En mi trabajo, por ejemplo, nadie me ha preguntado nada. Nadie sabe cómo es el estudio que yo hice en Alemania. Nadie me preguntó. 0 sea, no sé... si no necesitan saber, no quieren saber, si hay una negación, si es dejadez, no sé, pero objetivamente no..." (Entrevista a B.F., realizada por Soledad Lastra, CABA, 28/03/2013).
} 


\section{¿Víctimas de primera o de segunda categoría? La compleja construcción social de una "jerarquía de las víctimas" en la Argentina posdictadura (1983-1987)}

desarrollo de la transición y en el nuevo gobierno ${ }^{11}$. Estos elementos se fortalecieron en el marco de 1984 y 1985 con la edición del Informe Nuncá Más, que consagró la condición de "inocencia" para que las víctimas fuesen reconocidas como tales (Crenzel, 2010).

El cariz "inocente" operado por la despolitización narrativa de esos años cristalizó en algunas figuras sociales paradigmáticas que operaron acelerando esta jerarquización. Inés González Bombal (1995: 206) lo señaló con la noción de "hipervíctima": aquellas personas muertas o desaparecidas, principalmente niños, mujeres embarazadas y ancianos. En esta categorización también se consideró a los niños apropiados o nacidos en cautiverio de los que no se sabía su destino. Estas figuras fueron concentrando el trabajo del CELS, multiplicando sus informes sobre el tratamiento terapéutico de esos niños, sobre los modos de acompañar la restitución de sus identidades, entre otros temas ${ }^{12}$.

En este punto, podemos identificar que las fronteras de los escalafones tenían que ver mucho más con los alcances del dispositivo desaparecedor que con los perfiles de las víctimas. Por ejemplo, el equipo de salud mental de la OSEA-CELS atendió a un significativo sector de niños, mujeres y ancianos que vivieron el exilio y que regresaron con graves sintomatologías generadas por la experiencia exilar. En el caso de los niños, los síntomas se expresaban en crisis emocionales y alteraciones del desarrollo psico-físico y del lenguaje; mientras que en los adolescentes se manifestaba en reiterados intentos de suicidio. También se encontraban los ancianos, que se enfermaban por no poder continuar con los tratamientos iniciados en el exterior ${ }^{13} \mathrm{y}$ las mujeres que regresaban viudas, con parejas muertas $\mathrm{o}$ desaparecidas como consecuencia del accionar estatal (CAREF, Trabajo con retornados argentinos, 1984). Así vemos cómo se fue gestando un proceso de autonomización de la desaparición y de los desaparecidos que totalizó la identificación de la represión y de sus efectos con estas figuras, silenciando otras. Es

\footnotetext{
11 Sobre la escasa participación que tuvieron los exiliados en los partidos políticos argentinos de cara a la transición, ver Infesta Domínguez (1987); mientras que el importante papel que tuvieron algunos intelectuales retornados en el equipo de gobierno de Alfonsín se profundiza en Roniger et. al. (2018: 139 y ss).

12 Una lista incompleta de esos informes, incluye: Elsa Pavón, "Niños secuestrados y nacidos en cautiverio", 1987; Mirta Clara, "Niños detenidos desaparecidos. El derecho a recuperar su identidad", 1986; Marie Pascale, "Memoria para lo impensable. El caso de los hijos de desaparecidos robados por militares y policías", 1987; Abuelas de Plaza de Mayo, "Los niños desaparecidos. Su restitución", 1984; Abuelas de Plaza de Mayo, "La importancia de la restitución", s/f.

${ }^{13}$ CAREF señaló que en septiembre de 1984, de 300 familias entrevistadas, al menos 20 tenían como jefes de familia a personas transitando por la tercera edad. Hacia finales de 1984, preocupaba el caso de un "anciano que antes de salir estuvo detenido y torturado, que vivió su exilio en México y que regresó cuando tenía un hijo detenido, situación que lo expuso a un recrudecimiento de los trastornos físicos y psíquicos que sufrieron estos años. Estos problemas en el caso de la población mayor, son altamente generalizados" (CAREF, Proyecto de Rehabilitación de Retornados, 1984).
} 


\section{Soledad Lastra}

decir, que las "hipervíctimas" no eran tales sino habían pasado de alguna forma por el dispositivo de la desaparición.

\section{Los trabajadores de la salud mental frente al exilio y al concepto "Terrorismo de Estado"}

En esta segunda parte nos concentraremos en las dimensiones "micro" de este proceso, analizando especialmente el papel que tuvo el equipo de salud mental de OSEA-CELS. Recordemos que el CELS fue fundado en 1979 por un grupo de familiares cuyos hijos habían sido secuestrados y desaparecidos, y que fue Emilio Mignone quien estimuló el funcionamiento de la OSEA motivado por las crecientes consultas de exiliados argentinos que esperaban por regresar y dudaban sobre las condiciones judiciales y legales para poder hacerlo.

El equipo de Salud Mental de la OSEA-CELS estuvo dirigido por Laura Conte (psicóloga y esposa de Augusto Conte) e integrado por 40 profesionales que atendían las distintas situaciones de salud de los exiliados que volvían. Su creación fue novedosa pues si bien ya existían en los organismos de derechos humanos equipos de salud mental, estos se habían abocado a la atención de otros afectados por la represión y no de los exiliados. De ellos cabe destacar al equipo de la agrupación Madres de Plaza de Mayo que desde 1977 atendió a familiares de desaparecidos y que tuvo una incidencia importante en este imaginario jerarquizador, como vimos en el apartado anterior.

El área de salud mental para los exiliados se formó en el marco del Programa de Prevención y Asistencia en Salud Mental para los Afectados Directos de la Represión. Incluir a los exiliados en el universo de los afectados "directos" significó, en principio, equiparar el daño del exilio al de los familiares de los desaparecidos.

Esa línea se refuerza cuando vemos que el exilio fue considerado por este equipo como un trauma con síntomas específicos que respondían a un quiebre en la vida psíquica producido al salir del país (CELS, Informe del Equipo de Salud Mental, 1986). También afirmaron que el retorno conllevaba otros traumas pues las personas regresaban a un país generalmente idealizado (OSEA, Proyecto de Prevención y Asistencia en Salud Mental, s/f). El exilio y el retorno se definieron como experiencias de "trauma social", es decir, que el equipo reconocía una producción política del daño desestimando categorizaciones limitadas al campo de lo inconsciente. Como adelantamos, esto tenía que ver con una profunda transformación del campo "psi" en los años previos a la dictadura militar, en los que se recuperó la condición política y social como variable explicativa de los daños psíquicos. Ello, junto a la proliferación de ensayos y reflexiones que realizaron los psicólogos, psiquiatras y psicoanalistas exiliados, que intercambiaron ideas y reflexiones con el CELS, fortaleció la idea de que el exilio y el retorno también podían identificarse como "traumas" (Lastra, 2019).

Sin embargo, a lo largo de sus análisis, los integrantes del equipo fueron visibilizando las conexiones que el exilio tuvo con otros hechos represivos. Sobre un 


\section{¿Víctimas de primera o de segunda categoría? La compleja construcción social de una "jerarquía de las víctimas" en la Argentina posdictadura (1983-1987)}

total de 187 casos registrados en el área ${ }^{14}$, al menos un $46 \%$ de los casos podía definirse como personas afectadas "solamente" por el exilio, mientras que el resto se distinguía por una situación híbrida que podía incluir prisión política, secuestros, o la ausencia de un familiar desaparecido (CELS, Informe del Equipo de Salud Mental, 1986). Para sistematizar los cuadros psicológicos de cada paciente con las situaciones de violencia vividas en el pasado los trabajadores de la salud mental fueron organizando ${ }^{15}$ las "afecciones" que surgían de las consultas en un cuadro de datos. El registro de cada caso se transcribió en una secuencia de experiencias que iban surgiendo en el relato de las personas. Con fines ilustrativos, reproducimos los siguientes casos:

- Sexo femenino, 38 años, comenzó su asistencia en agosto de 1984, afectada por: "detenida-desaparecida. Tortura, secuestros hijos. Exilio";

- Sexo femenino, 35 años, comenzó su asistencia en octubre de 1984, afectada por: "secuestro. Tortura. Fuga y exilio. Esposo muerto";

- Sexo femenino, 43 años, comenzó su asistencia en abril de 1985, afectada por: "prisión. Tortura. Exilio";

- Sexo masculino, 64 años, comenzó su asistencia en noviembre de 1985, afectado por: "exilios sucesivos";

- Sexo masculino, 37 años, comenzó su asistencia en mayo de 1985, afectado por: "hermano desaparecido. Exilio";

- Sexo femenino, 65 años, comenzó su asistencia en septiembre de 1985, afectada por: "Exilio de un hijo";

- Sexo femenino, 28 años, comenzó su asistencia en junio de 1985, afectada por: "exilio de un hermano" (CELS, Informe del Equipo de Salud Mental, 1986, selección de casos).

Los casos mencionados forman parte de un registro mucho mayor y heterogéneo. Aquí recuperamos algunos para problematizar los nexos entre las experiencias represivas. Justamente en ellos se puede ver cómo el exilio se fue delineando a la luz de un entramado de vivencias exilares y no exilares, no siempre vividas en primera persona.

\footnotetext{
${ }^{14}$ Estos casos responden solamente a los que fueron registrados para el Informe aquí citado. No hemos podido corroborar la magnitud total de casos atendidos entre 1983 y 1986 por el equipo de salud mental, pero sabemos que entre 1984 y 1985, OSEA recibió 1168 y 2508 casos respectivamente, lo que podría señalar un universo bastante limitado de los datos registrados (OSEA, Informe sobre la actividad desarrollada por la Oficina de Solidaridad para Exiliados Argentinos y evaluación sobre su reinserción a la patria, 1988, p. 17).

${ }^{15}$ Este registro de casos es resultado de los datos que construyó el área de admisión del equipo de salud mental del CELS. Las historias clínicas no se encuentran a disposición del investigador, pero sí los registros organizados por los integrantes del equipo de salud mental entre los años 1981 y 1986 (CELS, Informe del Equipo de Salud Mental, 1986, p. 5).
} 


\section{Soledad Lastra}

En primer lugar, subrayamos que estar "afectado" por exilio no siempre respondía a una experiencia exilar propia sino que podía tener que ver con el exilio de un familiar (de un hijo o hermano, por ejemplo), con haber regresado y que parte de la familia se quedase en el exilio o bien con modalidades de la partida que hicieron que en muchos casos los familiares de desaparecidos en Argentina tuvieran que salir del país.

En segundo lugar, se evidencia la variedad de momentos en que se iniciaron las consultas y que no fueron inmediatas a la recuperación de la democracia. Del total de casos registrados, 134 iniciaron su terapia en 1985, mientras que 38 lo hicieron en 1984 y sólo 8 en $1983 .{ }^{16}$ La abrumadora mayoría de casos iniciados en 1985 expresa el modo en que las experiencias personales de retorno se fueron articulando con los procesos político-institucionales del país. Distintos cuadros de angustia y de fantasías persecutorias que comenzaron a manifestarse en 1985 tenían que ver no sólo con la represión del pasado sino con la actualización de ciertos traumas y miedos a la luz del Juicio a las Juntas que se estaba desarrollando por ese entonces. Así, los traumas del exilio estaban profundamente ligados a las condiciones políticas del retorno que, en el caso argentino, se construyeron al calor de la criminalización de la militancia y de la judicialización ya mencionada.

Por último, vemos que las detenciones, prisiones y desapariciones de integrantes del núcleo familiar y de amigos de las personas atendidas, en algunos casos se registraban como hechos unidos al exilio. Los secuestros, torturas, prisión política, y/o la desaparición temporal en algún centro clandestino de detención o el asesinato de algún familiar, emergen en los registros como daños ligados por la represión estatal sin que uno (la desaparición) prevalezca sobre los otros. Las experiencias eran registradas horizontalmente y en algunos casos, siguiendo las secuencias de las vivencias, sin que ello significara jerarquización. De hecho, en los síntomas manifestados, no siempre las personas con familiares desaparecidos o con experiencias de desaparición se acercaban a la clínica por ese tema. Por ejemplo, se registró el caso de una mujer de 40 años, "detenida-desaparecida. Tortura. Exilio" cuyo motivo de consulta fue señalado como "problemática de los hijos adolescentes". Otro caso fue el una pareja, una mujer y un hombre de 31 y 36 años respectivamente, que habían vivido el secuestro y la desaparición de familiares y su propio exilio, y cuyo motivo de consulta fue registrado como "dificultad de convivencia en el retorno" (CELS, Informe del Equipo de Salud Mental, 1986). Esto no quiere decir que las angustias no estuviesen ligadas a los hechos represivos vividos; lo que tratamos de mostrar es cómo en los registros no era natural la primacía de un dolor por sobre otro.

Vemos así que en los primeros años de la posdictadura los relatos sobre las experiencias represivas fueron objeto de sistematización por parte de los integrantes de la OSEA-CELS y que ello profundizó el conocimiento sobre sus

\footnotetext{
${ }^{16}$ Los 7 casos restantes se dividen en: 1 en 1981 que fue derivado de otro organismo de derechos humanos, 1 en enero de 1986 al cerrar el informe y de los otros 5 no se tuvo información (CELS, Informe del Equipo de Salud Mental, 1986).
} 


\section{¿Víctimas de primera o de segunda categoría? La compleja construcción social de una "jerarquía de las víctimas" en la Argentina posdictadura (1983-1987)}

conexiones. ${ }^{17}$ Sin embargo, ello no implicaba necesariamente la superioridad de la desaparición.

En 1986, el equipo OSEA-CELS anunció el cierre del Programa de salud mental de atención a los retornados ${ }^{18}$. En su informe final afirmó que ni el exilio ni otros hechos represivos se podían encontrar en "estado puro" (CELS, Informe del Equipo de Salud Mental, 1986). Al respecto subrayaron que si bien existían prioridades de algunos hechos represivos conforme a los diagnósticos y primeras consultas de los pacientes, lo cierto era que no primaba una experiencia por sobre otra sino que las vivencias se entremezclaban y mixturaban psíquicamente.

Esta noción analíticamente integradora del exilio en una matriz represiva mayor se fue nutriendo en los trabajos conjuntos de los integrantes del equipo de salud mental que, a partir de 1986, sólo pertenecían al CELS. ${ }^{19}$ El exilio fue ubicándose en las producciones escritas del área como una experiencia lo suficientemente significativa y disruptiva para ser identificada con peso propio a la vez que como un hecho vinculado con otras experiencias encadenadas de represión y violencia. Los trabajadores de la salud mental afirmaron que resultaba difícil comprender el daño de un hecho represivo particular sin tener en cuenta que la violencia estatal implementada era global, es decir, amplia y dirigida a toda la sociedad.

Esta caracterización de la violencia estatal tuvo al concepto "terrorismo de Estado" como pilar fundante. El uso de este concepto por parte del equipo nos permite plantear que fue justamente en ese pasaje, de la interpretación de la "violencia conectada" al "terrorismo de Estado" que la jerarquización pudo hallar un reducto analítico para comenzar a formalizarse.

El concepto "terrorismo de estado" se forjó al calor de la lucha antidictatorial impulsada por los organismos de derechos humanos locales y por los exiliados y agentes de la denuncia humanitaria en la arena internacional (Jensen, 2017). ${ }^{20}$ Este

\footnotetext{
17 Recordemos que tempranamente a la instauración de la dictadura militar, y a raíz de la desaparición de sus hijos, Emilio Mignone y Agusto Conte -fundadores del CELS- identificaron que la violencia estatal se caracterizaba por un movimiento reticular y expansivo, que configuraba un circuito represivo recorrido por las personas detenidas o perseguidas. En este circuito se combinaban los dispositivos legales con los clandestinos, a veces con el propósito de la dictadura de "blanquear" detenidos (CELS, 1981).

${ }^{18}$ Ello no significó el abandono de los casos pues OSEA delegó en el CELS la recepción y continuación de la atención psicológica, pero ya no en el marco de una sub área especializada en el exilio-retorno. Si bien esto pudo deberse a que el retorno masivo se produjo en el primer año del gobierno democrático (1984), lo cierto es que los efectos psicológicos del exilio y el retorno continuaron.

${ }^{19}$ Nos referimos a las Primeras Jornadas Nacionales sobre Problemas de Repatriación y Exilio (julio, 1984); Primer encuentro nacional Viejos y Nuevos problemas en salud y derechos humanos (marzo, 1986), Seminario Internacional Consecuencias de la Represión en el Cono Sur (mayo, 1986) y Jornadas "La psicología al servicio de los intereses populares: experiencias concretas" (junio, 1988). ${ }^{20}$ Una breve genealogía de su impacto en la lucha humanitaria inicia con el trabajo de la Comisión Argentina por los Derechos Humanos (CADHU) titulado "Argentina: proceso al genocidio" de los abogados Eduardo Luis Duhalde y Gustavo Roca en Ginebra en 1977. Cuatro año después, Mignone y Conte presentaron en París el Informe del CELS ya mencionado y por último, en 1984 se editó en Argentina el que fue un libro fundante para pensar la represión de la dictadura: "El estado terrorista Argentino", escrito por Duhalde en su exilio en Madrid.
} 


\section{Soledad Lastra}

concepto tuvo en el CELS un anclaje central por el papel que cumplieron sus abogados en la construcción de la evidencia sobre la violencia sufrida por las víctimas. Como señala Santiago Garaño (2019) siguiendo a Philips Abrams, el concepto "terrorismo de Estado" o "Estado terrorista" fue cimentado por el activismo de derechos humanos como una contra-idea-de Estado para evidenciar que los agentes e instituciones estatales cometían delitos y crímenes hacia la oposición política local estigmatizada como "terrorista". En efecto, la categoría fue migrando desde el ámbito de los derechos humanos a otras áreas de producción de conocimiento. En el caso del equipo de salud mental OSEA-CELS, es posible identificar la existencia de ciertos matices operados sobre el concepto en su apropiación semántica.

En su obra fundante, el abogado Eduardo Duhalde (2014:251) afirmaba que la cualidad sustancial del Estado terrorista consistía en la ejecución del terror social y en la aniquilación física de sus opositores. Sin embargo, en los informes y documentos internos de trabajo del equipo OSEA-CELS se incluyen otras facetas represivas del terrorismo de Estado que se articulaban con la eliminación física de las personas, como ya vimos anteriormente.

Por ejemplo, en 1987, el psicoanalista Juan Jorge Fariña señalaba en un informe del equipo de salud mental del CELS:

"lo esencial del Terrorismo de Estado es el carácter clandestino de la violencia represiva, con miras a desmoralizar y aterrorizar tanto a los opositores políticos activos como a la población en general (...) La política represiva, aplicada sistemática y masivamente, consistió en secuestros, desapariciones, torturas, fusilamientos, reclusión legal y exilio" (Fariña, 1987: 8).

La mención de las prácticas represivas no siempre conducentes a la aniquilación física es evidente. Ello se refuerza en el citado informe con un prolífico detalle de las características que asumió cada una de estas prácticas en la última dictadura militar. En efecto, podemos plantear que en estos años de la posdictadura, al interior de la categoría "Terrorismo de Estado" podían convivir experiencias de la represión no jerárquicas entre sí. Sin embargo, también es posible identificar en los documentos internos del equipo de salud mental, otros análisis en los que el exilio comenzó a ocupar un lugar periférico en relación a la desaparición. Para ello, recurrimos como ejemplo a otro informe de la OSEA-CELS que señala en los exiliados a personas que vivieron en "la lejanía del escenario del acontecimiento traumático y del brazo ejecutor de lo siniestro" a pesar de que "el exilio en sí mismo se pudiera constituir en un acontecimiento traumático a elaborar" (OSEA-CELS, La Familia, objetivo privilegiado de la acción siniestra del Terrorismo de Estado, Informe, mayo de 1986, pp. 2-3).

Los años 1986 y 1987 fueron centrales en la construcción de las interpretaciones sobre la violencia y sobre sus efectos en nuestra sociedad. La sanción de las leyes de Punto Final (Ley 23.492, diciembre de 1986) y Obediencia Debida (Ley 23.521, junio de 1987) obstaculizaron los avances judiciales sobre los crímenes cometidos por las 


\section{¿Víctimas de primera o de segunda categoría? La compleja construcción social de una "jerarquía de las víctimas" en la Argentina posdictadura (1983-1987)}

fuerzas militares e impactaron profundamente en las luchas de los organismos de derechos humanos. Ello tuvo también una gran repercusión en los análisis realizados por el equipo de salud mental del CELS pues a partir de allí, los distintos efectos represivos se fueron descentralizando, para dar paso a una narrativa que subrayó a los secuestros, las muertes y las desapariciones como las principales "aberraciones" de la metodología represiva (Juan Jorge Fariña, Paradigmas metodológicos y conceptuales en Salud Mental y derechos Humanos, Trabajo presentado en el Simposium sobre Psicología y Derechos Humanos, 1987, La Habana). Los intentos gubernamentales por clausurar el proceso judicial operaron en este sesgo, que se tradujo en el crecimiento sostenido de la producción escrita sobre la muerte, la desaparición y la incidencia que la impunidad tenía en la subjetividad dañada 21 .

La acumulación sobre el tema de los desaparecidos se reflejó también en los recursos a la bibliografía sobre el caso del nazismo y de sus campos de concentración para comprender la experiencia argentina. El "campo de exterminio" que también había sido fundante para el estudio de Duhalde, funcionó como una figura muy utilizada en la clínica del equipo de salud mental del CELS. ${ }^{22}$ Esta creciente primacía del dispositivo desaparecedor tuvo un efecto potenciador de la figura de los desaparecidos como las principales víctimas de la última dictadura militar.

"El desaparecido es un enigma de destino incierto. A él no podemos caracterizarlo y es a través del trabajo con el familiar donde somos convocados a develar el secreto que el enigma encierra. Qué le pasó, dónde está, cuál fue su destino y quiénes fueron los responsables de la desaparición" (Conclusiones del seminario Consecuencia de la Represión en el Cono Sur: sus efectos médicos, psicológicos y sociales, Uruguay, 18-23 de mayo de 1986, p. 11).

Lo desarrollado hasta aquí nos permite afirmar que el uso del concepto "terrorismo de Estado" fue convirtiéndose gradualmente en un marco de interpretación de la producción de saberes de los trabajadores de la salud mental frente al exilio, sin ser determinante en la operacionalización de la jerarquía de las víctimas. La especialista Gabriela Águila (2013) subraya que el concepto "terrorismo de Estado" invisibilizó la especificidad represiva de la dictadura militar a través de su carácter clandestino: opacó la selectividad y direccionalidad para aniquilar a la oposición política, soslayó la variedad de agencias estatales que funcionaron articuladas entre sí para concretar los crímenes y desdibujó las características de los distintos dispositivos represivos

${ }^{21}$ De la creciente producción del CELS sobre la impunidad y la subjetividad dañada, ver: Elena Aguiar, Algunas consideraciones sobre los efectos psicológicos de la impunidad en parejas afectadas directas por la represión política, s/f; María del Carmen Patrón y Carlos Etchegoyhen, Salud y Derechos Humanos, junio de 1988; CELS, Efectos de la impunidad en el sujeto y en el cuerpo social, 1989.

${ }^{22}$ Algunos materiales que remiten a esta figura: Sara Moscona, Los trabajadores de la salud mental frente a la problemática de los desaparecidos, 1985; Enrique Guinsber, Salud mental, paz y terrorismo de Estado, Nueva Sociedad, núm. 89, Mayo-junio de 1987, Caracas. 


\section{Soledad Lastra}

que alimentaron la "máquina terrorista". La noción de "terror" del "terrorismo de Estado" quedó restringida al "Estado clandestino" de Duhalde (2014:252), descuidando la contracara legal y normativa del Estado que el mismo autor señaló como un elemento fundamental para la comprensión del funcionamiento de la dictadura militar.

Actualmente la idea generalizada de "terrorismo de Estado" adjudica una direccionalidad a las experiencias de violencia estatal, imprimiendo un sentido teleológico a la desaparición de personas como fin último de la represión. Sin embargo esto no se reflejó inmediatamente en el campo de las víctimas pues, como mencionamos, existieron algunas interpretaciones que en la práctica homologaron los daños sin reconocer víctimas de primera ni de segunda categoría. Aquellas experiencias represivas con efectos no desaparecedores no siempre tuvieron un lugar subalterno en el relato sobre el "terrorismo de Estado"23. En el caso del exilio, su subsidiaridad fue el resultado de un proceso gradual y en conjunción con otros factores. En consecuencia, el concepto de "terrorismo de Estado" por sí solo no fundó escalafones pues ellos se fueron asentando semánticamente junto con las prácticas y sentidos construidos por los actores políticos y sociales en los álgidos y complejos años ochenta.

\section{Conclusiones}

A lo largo de este trabajo profundizamos en un problema complejo del campo de la historia social del pasado reciente argentino referido al proceso de jerarquización de las víctimas que se fue construyendo en la posdictadura.

En la narrativa hegemónica sobre la transición a la democracia, el terrorismo de Estado y los desaparecidos son actualmente las figuras nodales para su interpretación. El primero, como relato sobre el tipo de violencia impartido por el régimen militar y el segundo, como el paradigma de la víctima creada por el dispositivo desaparecedor como "el" dispositivo represor. Como mostramos en este artículo, este proceso encontró fuelles de amarre en distintos actores y escenarios: en los organismos de derechos humanos, especialmente en la agrupación de Madres; en los profesionales de la salud mental y en los mismos actores afectados por otras experiencias represivas no necesariamente ligadas a la desaparición de personas. Así, la "jerarquización del daño" sin ser una teoría elaborada explícitamente ni un objetivo de la violencia estatal, pudo ser un efecto no deseado y reproducido por distintas voces e imaginarios sociales.

El proceso judicial y las medidas políticas tomadas en el gobierno de Alfonsín contaron con elementos centrales para la consolidación de una "escala de dolores" sobre los efectos de la represión previa: la judicialización de todo tipo de violencia que persiguió a ex militantes y retornados del exilio; la estigmatización del exiliado

\footnotetext{
${ }^{23}$ Resulta importante reconocer la multiplicidad de apropiaciones y reinterpretaciones que existen sobre el concepto "terrorismo de Estado", muchas de las cuales fueron impulsadas por el mismo Duhalde en sus recurrentes revisiones sobre su obra original.
} 


\section{¿Víctimas de primera o de segunda categoría? La compleja construcción social de una "jerarquía de las víctimas" en la Argentina posdictadura (1983-1987)}

como sospechoso por "subversión" y la ausencia de un discurso y una política pública que alentara y facilitara el retorno de los expatriados.

Sin embargo, en este artículo nos detuvimos en otros factores sociales que operaron gradualmente en la posibilidad de que la jerarquización se consolidara.

En primer lugar, nos acercamos al rol que tuvieron las Madres de Plaza de Mayo frente al exilio. En esa exploración examinamos cómo en el proceso de silenciamiento o marginalidad del exilio en la "jerarquía de las víctimas", existieron prácticas de inclusión/exclusión de ciertos actores. El hecho de que durante la dictadura algunos actores tuviesen una mayor proyección internacional en su capacidad de hablar en nombre de "las víctimas", merece una investigación más profunda. Junto a ello, uno de los temas de agenda que abre esta investigación, consiste en revisar las relaciones y tensiones que se fueron estableciendo bajo la dictadura y en democracia entre los distintos organismos de derechos humanos con los actores del amplio campo del exilio, entre los que se incluyen los militantes de las organizaciones de izquierda armada.

En segundo lugar, analizando los sentidos y las prácticas de los trabajadores de la salud mental, pudimos identificar dos procesos paralelos que confluyeron en esta jerarquización. Por un lado, la existencia de ciertos sentidos mistificadores sobre las Madres de Plaza de Mayo y sobre los desaparecidos como figuras incuestionables del campo de los derechos humanos en Argentina. Por otro lado, reconstruimos y analizamos los conocimientos que el equipo de salud mental de la OSEA-CELS puso en juego a la hora de comprender al exilio como dispositivo represivo específico. Ello nos permitió relativizar el alcance del concepto de Terrorismo de Estado como matriz explicativa totalizante pues si por un lado, el concepto fue acuñado privilegiando al campo de concentración y a la desaparición como dispositivo y efecto principal de la última dictadura militar, por otro lado, pudimos ver cómo este concepto tuvo matices de interpretación por parte de la OSEA-CELS que hizo que, dispositivos como la cárcel y el exilio, también fuesen contemplados en él. Esa inclusión, sin embargo, fue coyuntural, pues a partir de la profundización del escenario de impunidad en 1986 y 1987, los desaparecidos ocuparon la atención analítica central en el trabajo del equipo de salud mental.

En tercer lugar, este artículo pudo mostrar cómo la pertenencia al campo de las víctimas requiere en alguna medida del autoreconocimiento de los afectados como tales. En el caso de los retornados del exilio, las distancias que asumieron frente al exilio como un daño "equiparable" al de otros efectos de la represión estatal contribuyeron al espacio periférico que posteriormente terminaron ocupando. Así podemos plantear que la ausencia de un grupo de afectados por el exilio pudo impactar en su limitada proyección en el campo de las víctimas, en dictadura y en democracia. Sobre este tema quedan muchas aristas por investigar.

En definitiva, el proceso de jerarquización de las víctimas en la posdictadura argentina respondió a una construcción social que tuvo elementos centrales 


\section{Soledad Lastra}

provenientes del campo semántico y de las prácticas psicológicas y sociales para atender los daños heredados. Los primeros años ochenta demuestran esa contingencia en la articulación de ciertos sentidos sobre las víctimas. Muchos de esos sentidos se mantienen sin desnaturalizar.

\section{Bibliografía}

Águila, G. (2013). La represión en la historia reciente argentina: perspectivas de abordaje, conceptualizaciones y matrices explicativas. Contenciosa. Revista sobre violencia política, represiones y resistencias en la historia iberoamericana (1). Recuperado de http://www.contenciosa.org/Sitio/VerArticulo.aspx?i=7

Águila, G.; Garaño, S. y Scatizza, P. (2016). Represión estatal y violencia paraestatal en la historia reciente argentina: nuevos abordajes a 40 años del golpe de Estado, La Plata: FAHCE-UNLP. Recuperado de: http://www.libros.fahce.unlp.edu.ar/index.php/libros/catalog/book/63

Alonso, L. (2008). El surgimiento del movimiento argentino por los derechos humanos en perspectiva comparada. Páginas. Revista digital de la Escuela de Historia (1), Universidad Nacional de Rosario. Recuperado de http://revistapaginas.unr.edu.ar/index.php/RevPaginas/article/view/152

Balbino, A. (2015). O exílio em machete: O retrato dos exilados na imprensa argentina durante a redemocratização (1982-1984) (Tesis de Maestría en Historia, inédita). Programa de Posgraduación en Historia, Universidade Estadual de Campinas, Brasil.

Bozzolo, R. (1986). Acerca del lugar de las Madres de Plaza de Mayo. En D. Kordon \& L. Edelman (comps.); Efectos psicológicos de la represión política, Buenos Aires: Sudamericana-Planeta.

Canelo, B. y Guglielmucci, A. (2005). (Re) aparecer en democracia: silencios y pasados posibles. Anuario de Estudios en Antropología Social (CAS-IDES).

Carpintero, E. \& Vainer, A. (2018). Las huellas de la memoria II. Psicoanálisis y salud mental en la Argentina de los '60 y '70. Tomo II: 1970-1983. Buenos Aires: Topia.

Centro de Estudios Legales y Sociales (CELS) (1981). El caso argentino: desapariciones forzadas como instrumento básico y generalizado de una política. La doctrina del paralelismo global. Trabajo presentado en Coloquio La Política de desaparición forzada de personas. París, 31 de enero y 1 de febrero de 1981. 


\section{¿Víctimas de primera o de segunda categoría? La compleja construcción social de una "jerarquía de las víctimas" en la Argentina posdictadura (1983-1987)}

Chama, M. (2015). Compromiso político y labor profesional. Estudios sobre psicología y abogados en los primeros setenta, Colección Entre los libros de la Buena Memoria, Los Polvorines: UNGS, UNLP, UNaM.

Comisión Argentina por los Derechos Humanos (CADHU). ([1977] 2014). Argentina. Proceso al genocidio, Buenos Aires: Colihue.

Crenzel, E. (coord.) (2010). Los desaparecidos en la Argentina. Memorias, representaciones e ideas (1983-2008). Buenos Aires: Editorial Biblos.

Cueto Rúa, S. (2010). HIJOS de víctimas del terrorismo de Estado. Justicia, identidad y memoria en el movimiento de derechos humanos en Argentina, 1995-2008, Revista Historia Critica (40), Bogotá. Recuperado de http://www.scielo.org.co/pdf/rhc/n40/n40a08.pdf

D’Antonio, D. (comp.) (2018). Violencia, espionaje y represión estatal. Seis estudios de caso sobre el pasado reciente argentino, Buenos Aires: Imago Mundi.

Duhalde, E. L. ([1983]2014), El Estado terrorista argentino. Buenos Aires: Colihue.

Fariña, J. (coord.) (1987). Salud mental y derechos humanos. Efectos psicológicos de la represión. Informe de avance, Buenos Aires, agosto de 1987.

Feld, C. y Messina, L. (2014), En torno a la palabra testimonial de los sobrevivientes: testigos legitimados y denegados de los centros clandestinos de detención en Argentina. Revista Tramas, Universidad Autónoma Metropolitana. División de Ciencias Sociales y Humanidades, Departamento de Educación y Comunicación, año 24, núm. 41, pp. 43-77. Recuperado de http://bidi.xoc.uam.mx/MostrarPDF.php

Franco, M. (2018). El final del silencio. Dictadura, sociedad y derechos humanos en la transición (Argentina, 1979-1983). Buenos Aires: Fondo de Cultura Económica.

Franco, M. (2014). "La "teoría de los dos demonios", un símbolo de la posdictadura en la Argentina. Revista A Contracorriente, North Carolina State University. Department of Foreign Languages and Literatures, vol. 11, num. 2. Recuperado de https://acontracorriente.chass.ncsu.edu/index.php/acontracorriente/article/view $L$

Franco, M. (2006). El exilio. Argentinos en Francia durante la dictadura. Buenos Aires: Siglo XXI. 


\section{Soledad Lastra}

Garaño, S. (2019). Notas sobre el concepto de Estado terrorista. Revista Question (61), Facultad de Periodismo y Comunicación Social, La Plata. Recuperado de https://perio.unlp.edu.ar/ojs/index.php/question/article/view/4997/4451

González Tizón, R. (2018). Militancia humanitaria y testimonio. Los sobrevivientes de "El Vesubio" y la denuncia de los crímenes de la última dictadura (1976-2016) (Tesis para obtener el grado de Doctor en Historia, inédita), Instituto de Altos Estudios Sociales, Universidad Nacional de General San Martín, Buenos Aires.

González Bombal, I. (1995). "Nunca Más”. El juicio más allá de los estrados. En C. Acuña \& C. Smulovitz (comps.) Juicio, castigos y memoria. Derechos humanos y justicia en la política argentina, Buenos Aires: Nueva Visión.

Infesta Domínguez, G. (1987). Visualización del exilio y del retorno en la sociedad argentina. (Tesis de Licenciatura en Sociología, inédita), Universidad de Buenos Aires.

Jelin, E. (2005). Los derechos humanos entre el Estado y la sociedad. En Suriano, J. (dir.). Nueva Historia Argentina, Tomo X, Dictadura y Democracia, Buenos Aires: Sudamericana.

Jensen, S. (2017). Los exiliados argentinos y las luchas por la justicia (1976-1981), Estudios. Revista del Centro de Estudios Avanzados (38), Universidad nacional de Córdoba. Recuperado de https://revistas.unc.edu.ar/index.php/restudios/article/view/19126

Jensen, S. (2014). Memorias lights, memorias anestesiadas. Reflexiones acerca de los olvidos del exilio en el relato público y social de los setenta en la Argentina. En P. Flier y D. Lvovich (coords.). Los usos del olvido. Recorridos, dimensiones y nuevas preguntas. Rosario: Prohistoria.

Jensen, S. (2008). ¿Por qué sigue siendo políticamente incorrecto hablar del exilio? La dificultosa inscripción del exilio en las memorias sobre el pasado reciente argentino (1983-2007). Páginas. Revista digital de la Escuela de Historia (1), Rosario. Recuperado de http://revistapaginas.unr.edu.ar/index.php/RevPaginas/article/view/177

Jensen, S. \& L. Montero (2018). Repensando las articulaciones entre experiencias represivas y militantes. Walter Calamita, de la Unidad Penitenciaria 4 a la "opción" italiana (1974-1983). Revista Historia Oral, Associação Brasileira de História Oral (21), Rio de Janeiro. Recuperado de https://revista.historiaoral.org.br/index.php?journal=rho\&page=article\&op=view \&path $\% 5 B \% 5 \mathrm{D}=752$ 


\section{¿Víctimas de primera o de segunda categoría? La compleja construcción social de una "jerarquía de las víctimas" en la Argentina posdictadura (1983-1987)}

Jensen, S. \& S. Lastra (edits). (2014). Exilios: militancia y represión. Nuevas fuentes y nuevos abordajes de los destierros de la Argentina de los años setenta. La Plata: EDULP.

L’Hoste, M. (1986). La desaparición. Efectos psicosociales en Madres. En D. Kordon \& L. Edelman (comps.) Efectos psicológicos de la represión política, Buenos Aires: Sudamericano - Planeta.

Lastra, S. \& Jensen S. (2014). La criminalización judicial de la militancia y su impacto en el retorno de los exiliados argentinos en la posdictadura. En Jensen, S. y Lastra, S. (edits). Exilios: militancia y represión. Nuevas fuentes y nuevos abordajes de los destierros de la Argentina de los años setenta, La Plata: EDULP.

Lastra, S. (2019). "Dejar de ser síntoma con el silencio". La inscripción del exilioretorno en el campo de la salud mental en la posdictadura argentina (1983-1986). Revista Tempo, Departamento de História e ao Programa de Pós-Graduação em História da Universidade Federal Fluminense, vol. 25, núm. 2. Recuperado de http://www.scielo.br/pdf/tem/v25n2/1980-542X-tem-25-02-496.pdf

Lastra, S. (2017). Dictaduras y retornos del exilio. Chile y Argentina en perspectiva comparada. Clepsidra. Revista Interdisciplinaria de Estudios sobre Memoria (núm. 7), IDES, Buenos Aires, pp. 120-136.

Recuperado

de http://ppct.caicyt.gov.ar/index.php/clepsidra/article/view/8439/pdf

Lastra, S. (2016). Volver del exilio. Historia comparada de las políticas de recepción en las posdictaduras de Argentina y Uruguay (1983-1989), Colección de Libros de la Buena Memoria, Los Polvorines: UNGS, UNaM, UNLP. Recuperado de http://www.libros.fahce.unlp.edu.ar/index.php/libros/catalog/book/77

Manzanares, M. (2016). Los psicoanalistas rioplatenses en el exilio. Diálogos, aportes y discusiones más allá de los divanes mexicanos (1974-1985). (Tesis de Maestría en Historia Moderna y Contemporánea, inédita), Instituto José María Luis Mora, México.

Merenson, S. (2014). Y hasta el silencio de tus labios. Memorias de las ex presas políticas del Penal de Villa Devoto en el transcurso de la última dictadura militar en Argentina, La Plata: Ediciones Al Margen.

Rodriguez, A. (2014). Entre la guerra y la paz: La posguerra de los ex-combatientes del Apostadero Naval Malvinas: Experiencias, identidades, memorias, Tesis 


\section{Soledad Lastra}

presentada en Universidad Nacional de La Plata, Facultad de Humanidades y Ciencias de la Educación para optar al grado de Doctora en Historia. Recuperado de http://www.memoria.fahce.unlp.edu.ar/tesis/te.918/te.918.pdf

Roniger, L.; Senkman, L.; Sosnowski, S. \& Sznajder, M. (2018). Exile, diáspora and return. Changing cultural landscapes in Argentina, Chile, Paraguay and Uruguay, Oxford University Press.

Slatman, M. \& E. Serra Padrós (2014). "Brasil y Argentina: modelos represivos y redes de coordinación durante el último ciclo de dictaduras del Cono Sur. Estudio en clave comparativa y transnacional". En S. Jensen \& S. Lastra (edits.). Exilios: militancia y represión. Nuevas fuentes y nuevos abordajes de los destierros de la Argentina de los años setenta, La Plata: EDULP.

Vecchioli, V. (2014). La recreación de una comunidad moral y la institución de un relato legitimo sobre los derechos humanos en la Argentina, Publicar-En Antropología y Ciencias Sociales (17), Colegio de Graduados en Antropología de la República Argentina. Recuperado de http://ppct.caicyt.gov.ar/index.php/publicar/article/view/4779

Vecchioli, V. (2001). Políticas de la Memoria y formas de clasificación social. ¿Quiénes son las "víctimas del terrorismo de Estado" en Argentina. En B. Groppo \& P. Flier (comps.) La imposibilidad del olvido, Recorridos de la Memoria en Argentina, Uruguay y Chile, La Plata: Al Margen.

Yankelevich, P. (2009). Ráfagas de un exilio. Argentinos en México (1974-1983). Ciudad de México: El Colegio de México.

\section{Entrevistas citadas}

Entrevista a Laura Bonaparte, realizada por Pablo Yankelevich, Ciudad de Buenos Aires, 3 y 6 de agosto de 1999. PEL/2/A/6, Archivo de la Palabra, UNAM, Ciudad de México.

Entrevista a Beatriz Aguad, realizada por Cecilia Guerrero, Ciudad de México, 21 de noviembre de 1997, 4 y 12 de marzo de 1998. PEL/1/A/29, Archivo de la Palabra, UNAM, Ciudad de México.

Entrevista a B.F, realizada por Soledad Lastra, CABA, 28/03/2013.

Entrevista a A.C., realizada por Soledad Lastra, CABA, 11/10/2013.

Recibido: 21/07/2019

Evaluado: $15 / 08 / 2019$

Versión Final: 01/10/2019 